\title{
EXERCÍCIO (I)LEGAL DA ENFERMAGEM: A REALIDADE DO CUIDADOR INFORMAL*
}

\author{
Maria Ribeiro Lacerda ${ }^{1}$, Ramone Aparecida Przenyczka²
}

\begin{abstract}
RESUMO: O cuidado domiciliar tem gerado um mercado de trabalho informal composto por pessoas leigas que cuidam de forma, às vezes, pouco efetiva e com baixa qualidade. Este trabalho é uma pesquisa descritivo-exploratória, com abordagem qualitativa, realizada com 22 cuidadores informais. Os objetivos foram: identificar os cuidados desenvolvidos por cuidadores informais no domicílio; justapor esses cuidados com a profissão de enfermagem e discuti-los à luz de suas questões éticolegais. Os resultados da pesquisa mostraram que os cuidadores informais realizam ações de enfermagem no domicílio como cuidados de higiene, administração de medicamentos, cuidados com a pele, troca de curativos, procedimentos invasivos e cuidados com sondas de alimentação.
\end{abstract}

PALAVRAS-CHAVE: Enfermagem; Cuidados domiciliares de saúde; Exercício profissional.

\section{(IL)LEGAL NURSING PRACTICE: THE INFORMAL CAREGIVER’S REALITY}

\begin{abstract}
Home care has generated an informal job market, taking up lay people who sometimes deliver inefficient lowquality care. It is a descriptive-exploratory research study with a qualitative approach carried out with 22 lay caregivers. The objectives were: to identify home care delivered by informal caregivers; to confront such care with nursing profession and discuss it in the light of ethical-legal issues. Research results evidenced that lay caregivers perform home nursing actions such as hygiene care, drug administration, skin care, dressing exchange, invasive procedures and feeding tube care.
\end{abstract}

KEYWORDS: Nursing; Home Health Care; Professional Practice.

\section{PRÁCTICA (I)LEGAL DE ENFERMERÍA: LA REALIDAD DEL CUIDADOR INFORMAL}

RESUMEN: La atención domiciliaria crea un mercado de empleo informal compuesto por personas legas y que ofrecen atención, algunas veces, poco eficaz y con baja cualidad. Este trabajo es una investigación descriptivo-exploratoria, con un enfoque cualitatvo, que se realizó con 22 cuidadores informales. Los objetivos fueron: determinar los cuidados desarrollados por cuidadores informales en el domicilio; hacer una relación entre eses cuidados y la profesión de enfermería y discutir sobre ellos a la luz de sus aspectos éticos y legales. Los resultados de la investigación mostraron que cuidadores informales realizan acciones de enfermería en el domicilio, como cuidados con higiene, administración de medicamentos, cuidados con la piel, intercambio de curativos, procedimientos invasivos y cuidados de sondas de alimentación.

PALABRAS CLAVE: Enfermería; Atención domiciliaria de salud; Práctica profesional.

*Artigo extraído da Monografia realizada por Rosana de Fátima Xavier (in memorian). Curso de Graduação em Enfermagem. Universidade Federal do Paraná-UFPR, 2004.

${ }^{1}$ Doutora em Filosofia. Coordenadora do Núcleo de Estudos, Pesquisa e Extensão em Cuidado Humano de Enfermagem-NEPECHE. Professora Adjunta do Departamento de Enfermagem da UFPR. Coordenadora do Programa de Pós-Graduação em EnfermagemMestrado-UFPR.

${ }^{2}$ Aluna do Curso de Graduação em Enfermagem da UFPR. Membro do NEPECHE.

Autor correspondente:

Maria Ribeiro Lacerda

Rua Padre Camargo, 120 - 80060-240 - Curitiba-PR

Recebido: 28/08/07

E-mail: lacerda@milenio.com.br Aprovado: 19/06/08 


\section{INTRODUÇÃO}

Dentre as áreas de atenção à saúde da população destaca-se, por seu crescimento exponencial, a assistência domiciliar, cuja base é o cuidado de enfermagem. Diversos fatores contribuíram para esse crescimento como o aumento do tempo de vida de doentes crônicos, o aumento da população idosa, a regulamentação dos planos de saúde e a tentativa de redução no custo em saúde. Assim, o tratamento no domicílio reduz significativamente os custos gerados pelo internamento hospitalar, diminui as sucessivas reinternações e traz benefícios para o paciente, uma vez que a proposta do cuidado domiciliar é a de que esse seja humanizado e individualizado, além de diminuir riscos como as infecções hospitalares ${ }^{(1)}$.

O cuidado domiciliar é um campo crescente de atuação da Enfermagem que está ganhando espaço dentro do mercado de trabalho em saúde, e exige dos profissionais maior autonomia, responsabilidade e competência técnica.

Na realidade brasileira, o trabalho em cuidado domiciliar, tanto na rede pública como na privada de atenção à saúde, não comporta um modelo de atendimento/cuidado domiciliar satisfatório para toda a população que esteja em condições necessárias para sua realização como: equipe de saúde, serviço de enfermagem que atue 14, 12 ou 6 horas no domicílio, além de materiais e equipamentos pertinentes para esse tipo de atendimento. Na prática, o que se encontra freqüentemente são pessoas da família assumindo o cuidado de seu familiar doente. Contudo, nem sempre elas estão preparadas para essa realidade, posto que nem todos estão dispostos a cuidar. Há que se considerar também o alto custo do serviço especializado oferecido pelas empresas de Home Care (cuidado domiciliar).

É importante destacar que as famílias, muitas vezes, não têm condições de cuidar de seus familiares e não possuem suporte social, nem possibilidades sócioeconômicas suficientes para contratação de profissionais, abrindo precedente para uma rede informal de trabalho de cuidados de saúde, principalmente de enfermagem ${ }^{(1)}$. Tais fatores acabam gerando um mercado de trabalho informal composto por pessoas leigas que se autodenominam enfermeiros, com remuneração inferior à dos profissionais de enfermagem. Elas desenvolvem atividades que englobam o cuidado de grande quantidade de idosos e a realização de procedimentos complexos que são exclusivos da profissão de Enfermagem, conforme explicitado na Lei do Exercício Profissional da Enfermagem $^{(2)}$. Nesse contexto, denominamos cuidadores informais a todos aqueles que praticam cuidado de forma não profissional.

As atividades desenvolvidas pelos cuidadores informais no domicílio, em determinadas situações, são de alta complexidade e sem supervisão de um profissional com competência legal, o que acarreta prejuízo no cuidado ao paciente, uma vez que esses cuidadores não sabem prever situações de risco. Para realizar o cuidado no domicílio é preciso ter conhecimento técnico e científico (e não um conhecimento do senso comum) para atender as necessidades do paciente. Esta é uma questão que merece atenção e precisa ser discutida com a categoria profissional, pois os cuidadores informais aprendem a realizar procedimentos com enfermeiros ou auxiliares de enfermagem que atuam no cuidado domiciliar, e muitas vezes treinam uma pessoa para dar seqüência ao cuidado, pois a família não tem condições financeiras para manter um cuidado especializado. Este pode ser um familiar ou uma pessoa contratada pela família que não está cientificamente e nem tecnicamente capacitada. Essa situação colabora para o surgimento do cuidador informal que exercerá indevidamente e ilegalmente a profissão de Enfermagem.

Ao considerarmos que um dos autores desta pesquisa trabalhou com o cuidado domiciliar e, durante sua experiência, deparou-se com situações que lhe despertaram questionamentos éticos e legais sobre as ações de cuidado dentro do domicílio, realizamos este estudo que teve como objetivos: identificar quais as atividades os cuidadores informais desenvolvem ao cuidar de pacientes no domicílio; justapor essas atividades com a profissão de Enfermagem; e discutir as atividades do cuidador informal à luz das questões ético-legais do exercício da enfermagem.

O agir do enfermeiro está baseado no entrelaçamento do conhecimento científico com os conhecimentos e princípios éticos adquiridos e construídos na sua trajetória existencial ${ }^{(3)}$. Sendo assim, é conveniente esclarecer alguns conceitos relativos à Ética, ao Exercício Profissional de Enfermagem e à atuação dos cuidadores informais. Por conseguinte, transpõem-se, a seguir, as diferenças entre profissão e ocupação, a responsabilidade do enfermeiro e a Lei do Exercício Profissional, além de considerações sobre 
o cuidado domiciliar, assim como as normas correlacionadas a ele.

Diferenciar ocupação e profissão permite entender que nem toda pessoa que desenvolve uma atividade laboral é profissional, pois essa condição requer qualificação e reconhecimento normativo de um conselho de classe.

Uma ocupação não é feita exclusivamente com a participação do profissional, visto que abrange o interesse de pessoas indiretamente influenciadas, quem o realiza e quem dele se beneficia. Já a profissão, refere-se ao trabalho que se pratica com habilidade a serviço de terceiros, ou seja, requer prática constante de um ofício ${ }^{(4)}$. Contudo, seja trabalho/ocupação ou profissão, o artigo $5^{\circ}$, XIII, da Constituição Federal ${ }^{(5-6)}$ afirma que "é livre o exercício de qualquer trabalho, ofício ou profissão, atendidas as qualificações que a lei estabelecer”. Estas supõem capacidade técnica e profissional com registro de seu título em órgão disciplinador do exercício ${ }^{(6)}$.

Há que se considerar que para ser profissão é preciso também uma organização de categoria profissional, associações e conselhos normativos, um corpo de conhecimento reconhecido pela comunidade científica, assim como atualização constante na área de atuação ${ }^{(7)}$. Nesse sentido, o cuidado domiciliar realizado pela enfermeira e pela equipe de enfermagem, sob a supervisão da primeira, é considerado uma atividade especializada, conforme Resolução no 290/2004 do Conselho Federal de Enfermagem $^{(8)}$.

O profissional de enfermagem que atua no cuidado domiciliar é autônomo, uma vez que tem liberdade de tomar decisões, e dentro do ambiente domiciliar, só pode contar consigo, aumentando a responsabilidade sobre suas decisões. A responsabilidade significa o quanto uma pessoa está obrigada a responder por seus atos ${ }^{(9)}$.

Como as demais profissões de livre exercício no país, a Enfermagem está regulamentada por uma lei que estabelece quem pode exercer legalmente essa profissão, e quais as qualificações necessárias: a Lei $\mathrm{n}^{0}$ 7.498, denominada Lei do Exercício Profissional de Enfermagem. Nela, efetivamente, nem mesmo os técnicos e auxiliares de enfermagem poderiam prestar serviços no domicílio, como profissionais autônomos, sem uma supervisão direta ou indireta do enfermeiro.

O cuidado domiciliar pode ser entendido como cuidado desenvolvido com o ser humano (clientes e familiares), no contexto de suas residências, e faz parte da assistência à saúde dos envolvidos. Compreende o acompanhamento, a conservação, o tratamento, a recuperação de clientes de diferentes faixas etárias, em resposta às suas necessidades e a de seus familiares ${ }^{(1)}$. É uma modalidade de atenção à saúde desenvolvida desde os tempos mais remotos, e que no Brasil, esteve muito relacionada à área de saúde coletiva. Apenas a partir da década de 1990, o cuidado domiciliar volta-se para o atendimento, principalmente, de pacientes portadores de agravo de longa duração, incapacitantes ou terminais ${ }^{(10)}$. Sendo assim, o seu desenvolvimento só pode ser assegurado se houver o acompanhamento direto ou indireto do enfermeiro, tanto na orientação e supervisão do cuidador, quanto no cuidado e orientação da família como um todo.

Quando um paciente passa a ser cuidado no domicílio, espera-se que esta seja a melhor opção para ele e para a família, que precisa de suporte para assumilo. Contudo, quando não está disposta ou impossibilitada a assumir tal função, a família nem sempre procura por profissionais capacitados. Desta forma, surge a figura dos cuidadores informais, também chamados de genéricos ou leigos, que realizam a assistência no domicílio. Estes não possuem habilidades nem capacitação para cuidar, necessitando de ajuda e orientação de enfermagem ${ }^{(11)}$.

Há que se destacar que a residência do paciente é um campo novo de trabalho para diversos profissionais, e uma alternativa para muitas pessoas com baixa qualificação, que frente ao desemprego, buscam novos espaços, entre eles, o trabalho (cuidado informal) remunerado em domicílios ${ }^{(12)}$.

No que diz respeito às atividades da Enfermagem em Domicílio-Home Care, há a Resolução 267/2001 do Conselho Federal de Enfermagem que, além de classificá-las de acordo com os níveis de complexidade, organiza a prática da enfermagem no cuidado domiciliar, valoriza e preserva suas ações, fortalecendo, conseqüentemente, a idéia de que o cuidado feito por um profissional com competência técnica e responsabilidade garante sua qualidade ${ }^{(13)}$. Outras normas, embora não específicas sobre o cuidado domiciliar, são passíveis de aplicação devido ao seu conteúdo e à rede de relações que esse tipo de cuidado origina.

O Código de Defesa do Consumidor (CDC) $)^{(14)}$, em seu art. $4^{\circ}$, objetiva o atendimento das necessidades dos consumidores, o respeito, a sua dignidade, saúde e segurança, a melhoria de sua qualidade de vida, assim como a harmonia das relações de consumo. Neste 
sentido, o cuidador informal ao realizar procedimentos no cuidado domiciliar, muitas vezes realiza tarefas sem possuir competência técnica para tal, e isto implica em situações de risco ou dano para o paciente. Neste caso, o consumidor tem amparo no referido código, no art. 14, pelo qual o fornecedor de serviço responde, mesmo sem culpa, pela reparação dos danos causados aos consumidores por defeitos relativos à prestação de serviço. Há, ainda, a Lei das Contravenções Penais ${ }^{(15)}$ que, no art. 47, prevê que é uma contravenção penal exercer profissão ou atividade econômica sem preencher as condições a que por lei está subordinado o seu exercício.

\section{METODOLOGIA}

Optou-se por uma pesquisa descritivoexploratória com abordagem qualitativa, que proporciona visão geral e aproximação de determinado fato, avaliando-o e preparando-o para novas pesquisas $^{(16)}$. Dela fizeram parte 22 cuidadores leigos que prestam algum tipo de cuidado no domicílio. Os critérios utilizados para sua participação foram: prestar assistência no domicílio, receber remuneração e não fazer parte da família do paciente, caracterizando um trabalho informal e sem qualificação dentro da prática de enfermagem no cuidado domiciliar.

Por se tratar de uma rede invisível de trabalhadores informais, uma vez que não existe nenhum tipo de registro dessa ocupação em órgãos reguladores, fiscalizadores ou de contagens estatísticas, os participantes foram encontrados através de uma Unidade de Saúde e de uma empresa que presta serviços domiciliares, todos da cidade de Curitiba/PR.

Os dados foram coletados mediante a técnica de entrevista semi-estruturada. Esse instrumento, era composto de dez perguntas dissertativas. O primeiro contato com o sujeito foi realizado por telefone, em que explicou-se o motivo da pesquisa, com posterior agendamento, em um local da preferência do entrevistado. As entrevistas foram realizadas no período de 10 de setembro a 04 de outubro de 2004.

O projeto de pesquisa foi submetido e aprovado pelo Comitê de Ética em Pesquisa sob número de registro CEP/SD: 007. SM.07/03-09. Os sujeitos desta pesquisa foram esclarecidos e tiveram assegurado o direito ao anonimato, a condifencialidade, de se excluírem a qualquer momento, e assinaram o Termo de Consentimento Livre e Esclarecido conforme estabelece a Resolução nº 196/96 do Conselho
Nacional de Saúde, que trata de pesquisa envolvendo seres humanos.

\section{APRESENTAÇÃO E DISCUSSÃO DOS DADOS}

As ações realizadas pelos cuidadores leigos no domicílio incluem cuidados de higiene, administração de medicamentos, cuidados com a pele, troca de curativos, procedimentos invasivos e cuidados com sondas de alimentação.

Entre as atividades de higiene e conforto, estão auxílios nos banho de leito e de aspersão e auxílio em outras atividades de higiene como oral e íntima, troca de fralda, tricotomia facial (Gráfico 1). Todos os 22 sujeitos realizam alguma dessas atividades.

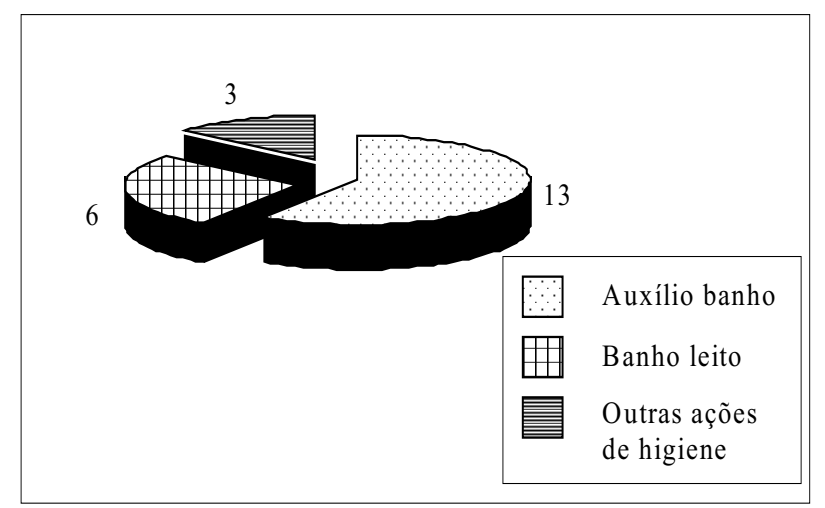

Gráfico 1 - Cuidados de Higiene. Curitiba, 2004

$\mathrm{O}$ art. 23 da Lei 7.498/86(2) informa que o pessoal que executa tarefas de enfermagem, em virtude de carência de recursos humanos de nível médio, sem possuir formação específica regulamentada em Lei, será autorizado, pelo Conselho Federal de Enfermagem-COFEN, a exercer atividades elementares de enfermagem. As atividades referidas são de fácil execução e entendimento, baseadas em saberes simples, que não requerem conhecimento científico, se restringem a situações de rotina e de repetição e não envolvem cuidados diretos ao paciente ${ }^{(17)}$, desde que desempenhadas sob orientação e supervisão de enfermeiro.

De acordo com este estudo, os cuidadores informais, inabilitados, administram medicação não só via oral, mas via intramuscular e subcutânea, preparam inalação, realizam controle de taxa de glicose através de dextro $(n=2)$ e controle de pressão arterial. O dado é preocupante devido aos riscos que a falta de conhecimento e os erros dessa prática podem oferecer ao paciente (Gráfico 2). 


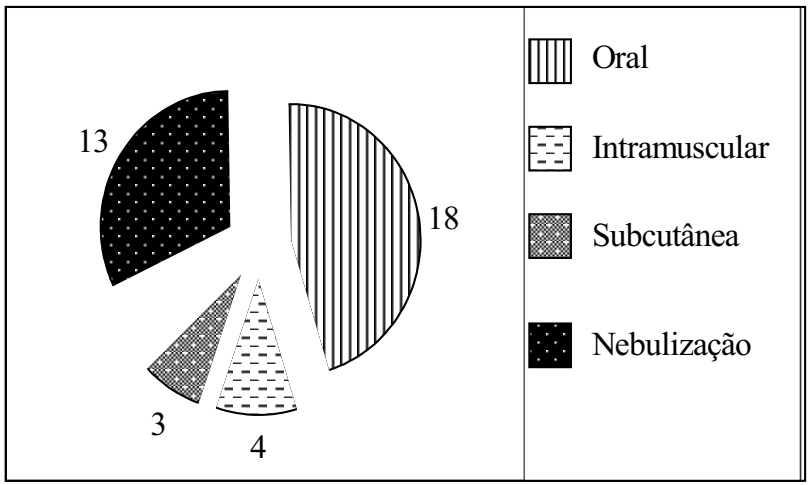

Gráfico 2 - Vias de administração de medicamentos. Curitiba, 2004

Desde que exercidas sob orientação e supervisão do enfermeiro, a administração de medicamentos pode ser delegada ao técnico ou ao auxiliar de enfermagem, sendo o que preceitua o art. 13 do Decreto ${ }^{\circ} 94.406 / 87^{(18)}$.

Os cuidados com a pele referem-se à aplicação de calor e frio (compressas), realização de curativos e cuidados com feridas. Desses, destacam-se os curativos realizados por 12 cuidadores informais, sendo que estes curativos não são simples, pois exigem avaliação e conduta específica (Gráfico 3).

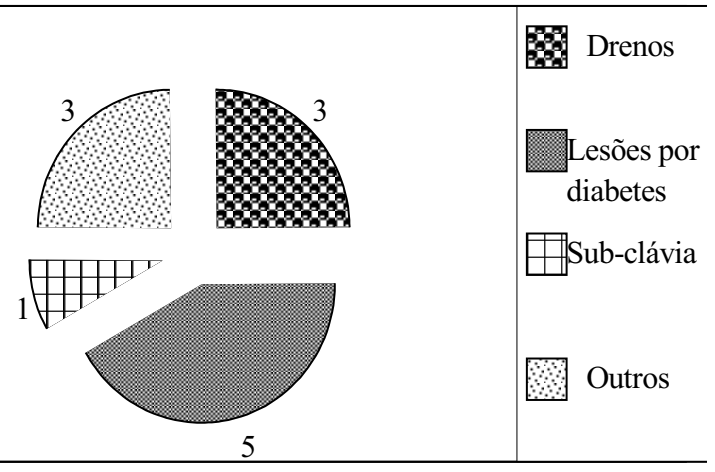

Gráfico 3 - Tipos de curativos realizados. Curitiba, 2004

Ressalta-se que, de acordo com art. $8^{\circ}, h$, do Decreto $n^{\circ} 94.406 / 87^{(18)}$, os cuidados de enfermagem de maior complexidade técnica e que exijam conhecimentos científicos, necessários à capacidade de tomar decisões imediatas, cabem privativamente ao enfermeiro. Entre seus fazeres está o tratamento de feridas e seu papel envolve conhecimento técnico para avaliação contínua das lesões e conhecimentos sobre a qualidade e quantidade de insumos utilizados; além disso, o enfermeiro deve integrar o conhecimento de enfermagem ao de outras disciplinas e ao de experiências anteriores para conhecer o risco da integridade cutânea e cicatrização da ferida(19-20).

Conforme a Resolução do COFEN 267/2001 ${ }^{(13)}$, as atividades de enfermagem desenvolvidas em domicílio são classificadas pelo grau de complexidade, e os curativos acima citados estão entre as atividades de média complexidade. Nestas, o cliente necessita de cuidados realizados com procedimentos técnicos científicos de Enfermagem que definirão o modelo assistencial aplicado à clientela, visando à diminuição do dano ou invalidez e necessidade de reabilitação. Essas atividades não estão simplesmente limitadas ao ato do fazer, mas envolvem conhecimentos específicos, avaliação do paciente e das ações, e exigem a presença do enfermeiro, uma vez que este possui competência técnica e científica.

No que se refere aos procedimentos invasivos, a situação é ainda mais alarmante, já que os dados mostram que 3 cuidadores informais administram medicação e alimentação via sonda nasoenteral e por ileostomia, 2 cuidadores passam sonda vesical de alívio e 4 realizam aspiração endotraqueal (Gráfico 4 ).

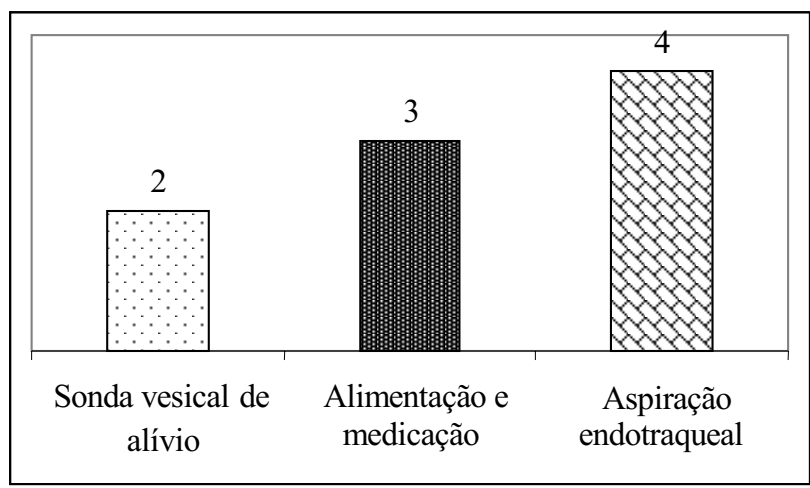

Gráfico 4 - Procedimentos invasivos. Curitiba, 2004

Os procedimentos executados pelos cuidadores informais exigem, além de habilidades, cuidados especiais, pois o risco de contaminação, desenvolvimento de infecções, aparecimento de lesões e outros danos, podem ocorrer, e eles não possuem conhecimento para prevê-los, tampouco para tomar decisões no caso de emergências. Essas atividades são caracterizadas como nível de alta complexidade, com a doença em curso, que assegura a complexidade do especialista em Enfermagem em domicílio ${ }^{(13)}$. A realização de procedimentos sem orientação de um profissional responsável, conforme a legislação vigente, pode colocar em risco a saúde do paciente, e configura uma atividade ilegal.

Na maioria dos casos, 16, a família é quem contrata os cuidadores, mas estes também podem ser 
contratados pelo próprio paciente. Outros são indicados por funcionários da casa, como empregados domésticos e auxiliares de enfermagem contratados anteriormente.

O cuidador é a pessoa que se envolve no processo de cuidar do outro, com qualidades pessoais de forte traço de amor, mas, ainda, é relevante e necessário considerar quais as conexões dessa atividade com a categoria da profissão de Enfermagem, e quais as implicações éticas advêm do direito do cidadão por um atendimento seguro e justo ${ }^{(1,21)}$.

A família acha que contratando outra pessoa para ajudá-la ou assumir o cuidado pode melhorar a qualidade da assistência, mas isto nem sempre ocorre, pois esse cuidado, muitas vezes, envolve conhecimentos científicos que requerem a presença do profissional de enfermagem sob a supervisão da enfermeira.

Dentre os entrevistados, 12 já vivenciaram o cuidado em outras situações, ou cuidando de seus familiares, ou como prestador de serviços em outros domicílios e estabelecimentos de saúde. Em virtude dessa "experiência" adquirida ao realizar cuidados, os mesmos se consideram aptos e capacitados a prestar serviços de enfermagem:

Já cuidei de outro paciente com diabete, fiz a faculdade da vida (A6).

Aprendi com minha irmã que é enfermeira [auxiliar de enfermagem] (A8).

Sim, cuidava de minha sogra quando ela estava acamada (A10).

A Enfermagem está relacionada à ciência do cuidado, porém, para o senso comum, ela é exercida por uma sucessão de seres humanos, no âmbito familiar ou em instituições de abrigos e/ou saúde ${ }^{(21)}$. Mas, por mais rica que seja a experiência da vida e mais completos os conhecimentos e a vivência, ainda assim não se constitui como saber, porque ser profissional é refletir sobre esse saber, interrogar-se sobre ele e problematizá-lo, caracterizando seus aspectos éticos e legais ${ }^{(22)}$.

Prestar cuidados de maneira autônoma, em domicílio, é uma prática exclusiva da enfermeira e, além de habilidades e experiências anteriores exige conduta específica, conhecimento científico, competência técnica, responsabilidade e registro em órgão disciplinador e fiscalizador ${ }^{(4,6,9)}$.

Dos entrevistados, 10 nunca desenvolveram ações de cuidado, sendo que cinco foram contratados com essa finalidade, e os demais já trabalhavam na casa como empregados domésticos, realizando cuidados a pedido dos patrões ou por achar que era sua obrigação:

Não, entrei como motorista e só faço os cuidados básicos; já fiz curso de primeiros socorros (A14).

Não, faço por necessidade. Alguém tem que fazer. Tenho orientação do médico e do motorista que tem curso de primeiros socorros (A16).

O ato de cuidar no domicílio exige do profissional um perfil próprio, além de conhecimento aliado ao saber/ fazer e responsabilidade técnica sobre seus atos ${ }^{(1)}$.

Os cuidadores informais que prestam cuidado no domicílio realizam atividades para as quais não estão aptos. Eles se sentem preparados para desenvolver tais atividades (Gráfico 5)?

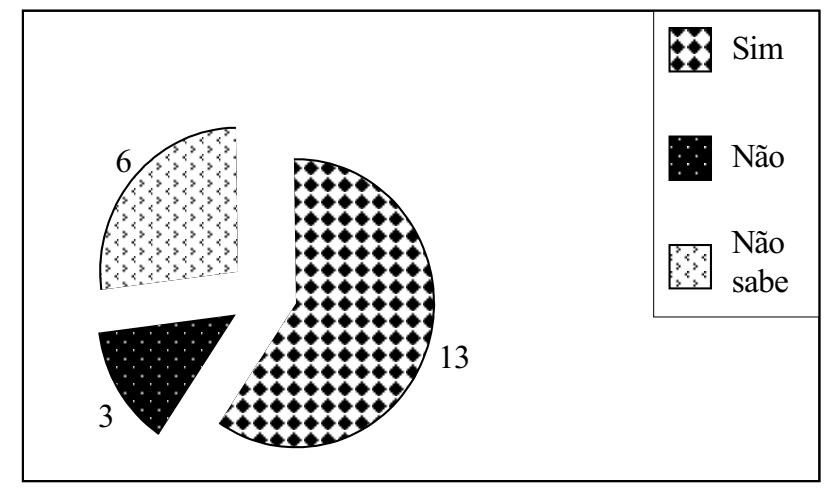

Gráfico 5 - Segurança para realizar os cuidados. Curitiba, 2004

Mais da metade dos entrevistados acha que estão preparados para realizar cuidados no domicílio, gostam de exercer o papel de cuidador, pensam que só é preciso seguir as prescrições médicas e ter paciência e consideram que estão prestando benefícios a outrem:

Me sinto amparada; faço o necessário conforme orientação do médico (A13).

Sim, e adoro o que faço (A12).

Este é um ato de caridade (A4).

Os cuidadores se valem de estratégias como solidariedade e paciência, provocando um rompimento entre o saber/fazer tradicional e um novo saber/fazer que está sendo reinventado e socializado pelas famílias $^{(23)}$. Mas, o preparo vem do conhecimento de 
como fazer, no sentido de compreender a extensão de seu ato, e deve envolver discussões éticas que permitam compreensão acerca deste trabalho(4,21).

Para relembrar, o art. $2^{\circ}$, § único, da Lei 7.498/ $86^{(2)}$, reza que "a enfermagem é exercida privativamente pelo Enfermeiro, pelo Técnico de Enfermagem, pelo Auxiliar de Enfermagem e pela Parteira respeitados os respectivos graus de habilitação".

Somente dois dos cuidadores entrevistados recebem supervisão de profissional capacitado, dez não recebem nenhum tipo de supervisão e dez recebem orientações de outros profissionais como médicos, fisioterapeutas e auxiliares de enfermagem.

O enfermeiro é o profissional fundamental do cuidado realizado no domicílio, pois está capacitado para classificar a complexidade do atendimento, a instabilidade de alguns estados de alterações fisiopatológicas e psicossociais, e é responsável direto pelo planejamento, organização, avaliação e acompanhamento do cuidado de enfermagem, que é o diferencial no atendimento eficaz e de qualidade.

De acordo com o art. 73, da Resolução do COFEN 311/2007(24), o enfermeiro está proibido de "trabalhar, colaborar ou acumpliciar-se com pessoas físicas ou jurídicas que desrespeitem princípios e normas que regulam o exercício profissional de Enfermagem.

As dúvidas mais comuns que os cuidadores informais relataram diz respeito à administração e controle de medicação relacionadas à diabetes, pressão arterial e ao estado de ansiedade do paciente conforme se observa na Tabela 1.

Tabela 1 - Dúvidas na realização dos cuidados. Curitiba, 2004

\begin{tabular}{lc}
\hline Dúvida apresentada & $\mathrm{N}^{\circ}$ de cuidadores \\
\hline Não tem dúvidas & 11 \\
Tem algumas dúvidas & 2 \\
É só ter paciência & 1 \\
Já está acostumada & 1 \\
Realiza o que está ao alcance & 1 \\
Nunca sabe se faz o certo & 1 \\
No controle da diabete & 1 \\
Quando deve dar remédio da pressão & 1 \\
Quanto ao remédio da depressão & 1 \\
Com medicação e aspiração & 1 \\
Com dor e vômito & 1 \\
\hline Total & 22 \\
\hline
\end{tabular}

Realizar atividades sem a capacitação para tal, desconhecendo os riscos, é um ato de negligência e desonestidade $^{(3)}$. Da entrevista, percebe-se a falta de conhecimento, a insegurança e o risco que pode acarretar para o desenvolvimento correto das funções relativas ao cuidado com a medicação:

Às vezes, mesmo depois de dar o remédio, a pressão continua alta (A13).

É preciso ter muita atenção, se a diabete sobe para dar o remédio certo (A1).

Tem dias que ela quer tomar o remédio da depressão mais de uma vez, e não pode. Aí eu só dou meio (A2).

Quando ocorrem dúvidas, a atitude mais comum entre os cuidadores é comunicar o médico do paciente e a família (Tabela 2). Os sujeitos emitiram mais de uma resposta, portanto, 25 é o número de respostas.

Tabela 2 - Atitudes no caso de dúvidas

\begin{tabular}{lc}
\hline Atitude do cuidador & $\mathrm{N}^{\mathrm{o}}$ de cuidadores \\
\hline Com dúvidas não faz & 1 \\
Chama o médico e a família & 11 \\
Chama o serviço de atendimento de & 1 \\
urgência e emergência privado & \\
Avisa a família & 4 \\
Fala com equipe de enfermagem & 6 \\
Chama um especialista & 1 \\
Não tem dúvidas & 1 \\
\hline Total & 25 \\
\hline
\end{tabular}

Os seis entrevistados que disseram recorrer à "enfermeira" que trabalhava na casa em outro turno foram agrupados em: "falava com a equipe de enfermagem", contudo, essa equipe se tratava de auxiliares de enfermagem. Esse dado demonstra a falta de conhecimento de cuidadores a respeito do papel do enfermeiro dentro do cuidado domiciliar e a confusão que pessoas, pelo senso comum, normalmente fazem com as categorias em que está subdividida a profissão de Enfermagem. Além de recorrer a um profissional que não possui competência para dar esclarecimentos, orientações e resolver problemas, tal atitude pode agravar o problema se a decisão não for apropriada.

Outra questão abordada na pesquisa foi como os 
cuidadores agiriam no caso de emergência (Tabela 3).

Tabela 3 - Condutas no caso de emergência. Curitiba, 2004

\begin{tabular}{lc}
\hline Conduta do cuidador & $\mathrm{N}^{\circ}$ de cuidadores \\
\hline $\begin{array}{l}\text { Chama o serviço de atendimento de } \\
\text { urgência e emergência privado }\end{array}$ & 8 \\
$\begin{array}{l}\text { Chama o serviço de atendimento de } \\
\text { urgência e emergência público }\end{array}$ & 2 \\
Avisa a enfermeira do Posto & 1 \\
Liga para o responsável & 3 \\
Nunca houve emergência & 4 \\
Fica nervosa & 1 \\
Faz Primeiros Socorros & 1 \\
Fica ao lado do paciente & 1 \\
Leva ao médico & 1 \\
\hline Total & 22 \\
\hline
\end{tabular}

Os entrevistados em sua maioria, 14 , relatam que sua conduta seria chamar o serviço de atendimento de urgência e emergência privado, avisar o responsável ou a enfermeira do posto e o médico. Quatro disseram nunca ter ocorrido uma emergência, e um deles faz o atendimento de primeiros socorros, porque fez curso e se sente capacitado.

Um dos cuidadores relatou não saber o que fazer, e outro considera que a única coisa que está ao seu alcance é ficar ao lado do paciente. O autocontrole e a percepção de prioridades são fundamentais para agilizar a conduta, ao passo que a ansiedade pode desencadear atropelos, resultando em agravos e seqüelas incapacitantes ${ }^{(21)}$.

O profissional de enfermagem, capacitado para prestar assistência no domicílio, reconhece situações de risco e sabe identificar sinais e sintomas relevantes e que exigem condutas imediatas.

Os cuidadores informais que prestam algum tipo de cuidado no domicílio, em sua maioria não têm conhecimento de que estão exercendo ilegalmente atividades de enfermagem. Dentre os 22 entrevistados, mais da metade não tem nenhum conhecimento ou nunca ouviu falar sobre os aspectos legais envolvidos em sua prática. Esse fato demonstra sua falta de esclarecimentos sobre a profissão de Enfermagem e a regulamentação dessa prática profissional. Prestam cuidados de enfermagem sem discernimento de seus atos, desconhecendo que a profissão de Enfermagem requer conhecimentos e qualificação e que procedimentos, por mais simples que pareçam, precisam ser supervisionados, enquanto os mais complexos não devem de forma alguma ser realizados por eles.

A Enfermagem é uma profissão compreendida como arte e ciência. Embora vista pelo senso comum como um simples ato de fazer cuidados, essa prática requer um saber específico, habilidades, competência e responsabilidade sobre seus atos, o que constitui seu diferencial ${ }^{(16-21)}$. Desta forma, o cuidado exercido por cuidadores informais precisa ser repensado e discutido, uma vez que está sendo confundido com a prática da enfermagem no âmbito domiciliar.

Três dos entrevistados têm algum conhecimento sobre os riscos de realizar procedimentos que não lhes competem, mas ainda assim não se negam a fazê-los, mesmo que isso acarrete em prejuízo para si ou para o paciente.

Os órgãos de fiscalização têm, por conseguinte, um papel relevante de garantia sobre a qualidade dos serviços prestados e da conduta humana dos profissionais. A fiscalização do exercício da profissão compreende as fases preventiva (ou educacional) e executiva, nas quais há verificação da qualidade das práticas $^{(4)}$.

\section{CONSIDERAÇÕES FINAIS}

Questões éticas muito sérias e complexas envolvem o cuidado praticado fora do ambiente hospitalar, que devem ser refletidas e discutidas, essencialmente dentro da categoria de Enfermagem, que depois do próprio paciente, representa a classe mais prejudicada com o aparecimento desse novo segmento denominado cuidadores informais/leigos e/ ou acompanhante de idosos. Estes realizam procedimentos que são de exclusiva competência dos profissionais de enfermagem, com pouco ou nenhum conhecimento de suas ações.

Discutir a ética e a legalidade que envolve as ações de cuidadores leigos não significa criar verdades absolutas, e sim refletir profundamente sobre esse cuidar e suas implicações, assim como sobre as responsabilidades e os danos que podem refletir no futuro da Enfermagem. Capacitá-los e inseri-los no mercado de trabalho não pode ser considerado como uma alternativa de suprir a demanda crescente da população, nem a carência de profissionais capacitados para prestar cuidado no domicílio.

Compreendemos que este estudo é preliminar, 
mas fornece subsídios para outras pesquisas, além de ser uma forma de denúncia sistematizada que deve chegar ao conhecimento de órgãos fiscalizadores competentes, e publicado em veículos de informação, para esclarecimento da população. Também serve para que a categoria se mobilize, no sentido de discutir e analisar os aspectos éticos que envolvem este cuidar.

\section{REFERÊNCIAS}

1. Lacerda MR. Tornando-se profissional no contexto domiciliar - vivência do cuidado da enfermeira [tese]. Florianópolis (SC): Universidade Federal de Santa Catarina; 2000.

2. Brasil. Lei $n^{\circ}$ 7.498, de 25 de junho de 1986. Dispõe sobre a regulamentação do exercício da enfermagem e dá outras providências. Diário Oficial da República Federativa do Brasil, Brasília, 26 jun. 1986. Seção 1:1.

3. Mazur CS, Labronici L, Wolff LDG. Ética e gerência no cuidado de enfermagem. Cogitare Enferm. $2007 \mathrm{Jul} / \mathrm{Set}$; 12(3):371-6.

4. Sá AL. Ética profissional. $4^{\mathrm{a}}$ ed. São Paulo: Atlas; 2001.

5. Brasil. Constituição da República Federativa do Brasil.

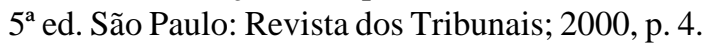

6. Oguisso T; Schmidt MJ. O exercício da enfermagem: uma abordagem ético-legal. São Paulo: LTr; 1999.

7. Machado MH. Profissões de saúde: uma abordagem sociológica. Rio de Janeiro: FioCruz; 1995.

8. Conselho Federal de Enfermagem. Resolução Cofen 290/2004 de 24/mar/2004. Fixa as especialidades de enfermagem. Rio de Janeiro, 2004. [Acesso em $15 \mathrm{abr}$ 2007]. Disponível em www.corenpr.org.br/legislacao/

9. Mora JF. Dicionário de filosofia. São Paulo: Edições Loyola; 2001.

10. Paz AA, Santos BRL. Programas de cuidado de enfermagem domiciliar. Rev Bras Enferm. 2003 Set/Dez; 56(5):538-41.

11. Fialho AVM, Pagliuca LMF. Adequação da teoria do déficit do autocuidado no cuidado domiciliar à luz do modelo de Barnum. Rev Latino-Am Enferm [periódico na Internet]. 2002 Set/Out [acesso em 2007 Fev 13]10 (5). Disponível em: www.scielo.br

12. Kawasaki K, Diogo MJD. Assistência domiciliária ao idoso: perfil do cuidador formal - parte II. Rev Esc
Enferm USP. 2001;35(4):320-7.

13. Conselho Federal de Enfermagem. Resolução Cofen 267/2001 de 05/outubro/2001. Aprova atividades de enfermagem em domicílio home care. Rio de Janeiro, 2001. [Acesso em 15 abr 2007]. Disponível em www.corenpr.org.br/legislacao

14. Antonio LAC. Código do consumidor comentado. São Paulo: Maksoud Plaza; 1992.

15. Brasil. Decreto $n^{\circ} 3.688$, de 3/10/1941. $23^{\mathrm{a}}$ ed. São Paulo: Saraiva; 1985.

16. Wood GL, Haber J. Pesquisa em enfermagem: métodos, avaliação crítica e utilização. Rio de Janeiro: Guanabara; 2001.

17. Conselho Federal de Enfermagem. Resolução Cofen 186/1995 de 20/julho/1995. Dispõe sobre a definição e especificação das atividades elementares de enfermagem executadas pelo pessoal sem formação específica. Rio de Janeiro, 1995. [Acesso em 02 jun 2007]. Disponível em www.corenpr.org.br/legislacao

18. Decreto n. 94.406/87, de 08 de junho de 1987 . Regulamenta a Lei n. 7.498 de 25 de junho de 1986 que dispõe sobre o exercício da enfermagem e dá outras providências. Brasília, 1987. [Acesso em 15 abr 2007]. Disponível em http://www.corenpr.org.br/legislacao

19. Baptista CMC, Castilho V. Levantamento do custo do procedimento com bota de Unna em pacientes com úlcera venosa. Rev. latino-am. enfermagem [periódico na Internet]. 2006 nov-dez [acesso em 01 jun 2007]; 14 (6): 538-541. Disponível em: www.scielo.br

20. Potter PA, Perry AG. Fundamentos de enfermagem. $6^{\mathrm{a}}$ ed. Rio de Janeiro: Elsevier; 2005.

21. Duarte YAO, Diogo MJD. Atendimento domiciliar: um enfoque gerontológico. São Paulo: Atheneu; 2000.

22. Pinto TM, Souza ML. Filosofia na enfermagem: algumas reflexões. Pelotas: UFPel; 1998.

23. Sena RR, Leite JCA, Costa FM, Santos FCO, Gonzaga RL. O cuidado no domicílio: um desafio em construção. Cogitare Enferm. 1999 Jul/Dez;4(2):58-62.

24. Conselho Federal de Enfermagem. Resolução Cofen 311/2007 de 08/02/2007. Aprova a reformulação do código de ética dos profissionais de enfermagem. Rio de Janeiro, 2007. [Acesso em 22 mai 2007]. Disponível em www.portalcofen.gov.br. 